\title{
ANALISIS PENERAPAN HEDGING DI PERBANKAN SYARIAH INDONESIA
}

\section{ANALYSIS OF THE IMPLEMENTATION OF ISLAMIC HEDGING AT THE INDONESIA}

\author{
Lina Ade Chusmita1a; Sahlan Hasbi²b \\ 1aProgram Studi Ekonomi Islam Fakultas Ekonomi Islam Universitas Djuanda Bogor, Jl. \\ Tol Ciawi No. 1, Kode Pos 35 Bogor 16720 \\ 2bProgram Studi Perbankan Syariah Fakultas Ekonomi Islam Universitas Djuanda Bogor, \\ Jl. Tol Ciawi No. 1, Kode Pos 35 Bogor 16720
}

(Diterima oleh Dewan Redaksi 10-06-2016)

(Dipublikasikan oleh Dewan Redaksi 01-12-2016)

\begin{abstract}
This research aims to determine the application of hedging in Islamic Banking Indonesia in mitigating the market risk resulting from fluctuations in foreign currency exchange rates. Researchers using qualitative methods, techniques Miles and Huberman Model. The object of this study is that adopted sharia hedging instrument of Conventional Banking products and prescribed and packaged in provisions DSN-MUI Fatwa No. 96/DSN-MUI/IV/2015, PBI 18/2/PBI/2016 and DPS Opinion No. 17/26/DPS/XII/2015 concerning the Proposed Transaction Hedging (Hedging) Sharia. The purpose and object of concern to researchers, then pure researchers took samples at PT. Bank Syariah Mandiri (BSM) that have implemented sharia hedging through forward contracts agreement. The results of this study, it can simply be concluded that the application of hedging has been implemented by BSM in accordance with the provisions of both the provisions of the DSN-MUI, PBI and DPS. But on the other hand there are things that must be considered more serious for banks to implement sharia hedging instruments. This is because there is the inherent nature of the hedging diinstrument which is difficult to be avoided and eliminated.
\end{abstract}

Keywords: Hedging, Forward Contract Agreement

\section{ABSTRAK}

Penelitan ini bertujuan untuk mengetahui penerapan hedging di Perbankan Syariah Indonesia dalam memitigasi risiko pasar akibat dari fluktuasi kurs valas. Peneliti menggunakan metode kualitatif, dengan teknik Model Miles and Huberman. Adapun obyek dari penelitian ini adalah instrumen hedging syariah yang diadopsi dari produk Perbankan Konvensional, lalu disyariahkan dan dikemas dalam ketentuan Fatwa DSNMUI No. 96/DSN-MUI/IV/2015, PBI No. 18/2/PBI/2016 dan Opini DPS No. 17/26/DPS/XII/2015 tentang Rencana Transaksi Lindung Nilai (Hedging) Syariah. Dari tujuan dan obyek yang menjadi perhatian peneliti, kemudian peneliti murni mengambil sampel di PT.Bank Syariah Mandiri (BSM) yang telah menerapkan hedging syariah melalui kontrak forward agreement. Hasil dari penelitian ini, secara sederhana dapat disimpulkan, bahwa penerapan hedging yang telah diterapkan oleh BSM telah sesuai dengan ketentuan, baik ketentuan dari Fatwa DSN-MUI, PBI maupun DPS. Akan tetapi disisi lain ada hal yang harus menjadi pertimbangan lebih serius bagi bank untuk 
menerapkan intrumen hedging syariah. Hal ini dikarenakan terdapat sifat yang melekat diinstrument hedging tersebut yang memang sulit untuk dihindari dan dihilangkan.

Kata kunci : Hedging, Contract Forward Agreement.

Lina Ade Chusmita. 2016. Analisis Penerapan Hedging di Perbankan Syariah Indonesia. (6): $292-299$

\section{PENDAHULUAN}

Perkembangan dan pertumbuhan perbankan syariah, bukan berarti tidak diimbangi oleh risiko.Mengingat dalam perkembangan dan pengembangan produk perbankan syariah tidak hanya untuk transaksi dalam negeri saja, melainkan juga mencakup transaksi luar negeri. Maka, perbankan syariah Indonesia diharapkan dapat mempersiapkan penanganan mengenai permasalahan yang dimungkinkan terjadi, salah satunya adalah permasalahan mengenai perubahan nilai tukar mata uang yang tidak menentu, seperti tergambar pada gravik berikut:

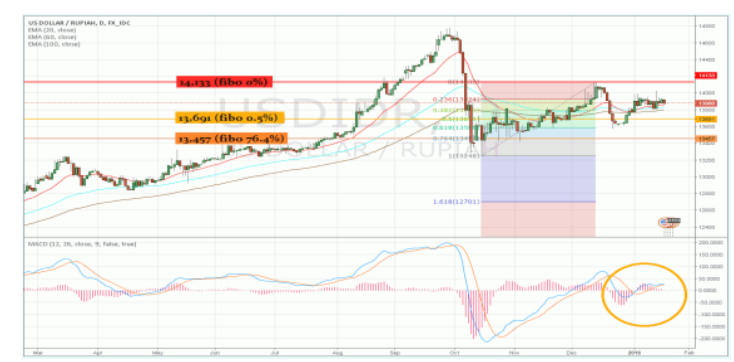

Gambar 1.

Nilai Tukar Rupiah/USD 18-29 Januari 2016

Terlihat pada gambar di atas, pergerakan nilai tukar rupiah dimungkinkan memberikan imbas yang tidak menguntungkan, mengingat hutang luar negeri Indonesia didominasi Dollar AS semakin meningkat. Hal ini dikhawatirkan apabila nilai rupiah terhadap USD jatuh dan perusahaanperusahaan belum melakukan hedging(lindung nilai) terhadap transaksinya, makadimungkinkan akan memberikan poin negatif terhadap perekonomian, ditambah dengan tingginya ketidak pastian di pasar global.

Berdasarkan hal tersebut bank syariah mengindikasikan bahwa perlunya suatu instrumen untuk menjaga atau mengurangi risiko akibat fluktuasi kurs rupiah, karena tidak ada yang dapat memastikan keadaan di masa mendatang. Kemudian perbankan syariah memilih suatu alternatif hedging (lindung nilai) sebagai alternatif untuk menekan risiko fluktuasi nilai tukar. Dengan instrumenhedging, maka nilai tukar rupiah dapat lebih terkendali. Sebelum munculnya konsep hedging di syariah khususnya di Indonesia, hedging telah diimplementasikan oleh perbankan konvensional dalam berbagai bentuk transaksi keuangan seperti:forward, option, future dan swap. Namun, dalam praktiknya hedging syariah yang dibolehkan diterapkan di Indonesia berdasarkan Fatwa Dewan Syariah nasional melalui Fatwa NO: 96/DSNMUI/IV/2015 tentang hedging hanyalah melalui instrumen forward agreement, untuk kebutuhan yang sifatnya urgent (lil hajah).

\section{MATERI DAN METODE}

Jenis penelitian ini adalah deskriktif kualitatif yang ingin memberikan gambaran tentang praktik hedging yang akan diterapkan di perbankan syariah Indonesia. Teknik pengumpulan data yang dilakukan menggunakan metode wawancara atau interview secara langsung kepada beberapa pihak seperti divisi treasury pada BSM yang telah mempraktikan sistem hedging, beberapa 
ahli fikih yang mengetahui praktik hedging yang sesuai dengan prinsip atau kaidah-kaidah syariah (hukum Islam) dan didukung dengan beberapa data lainnya.

Metode pengelolaan data dan analisis data menggunakan metode Miles and Huberman yang merupakan suatu model pengumpulan data dari beberapa sumber, baik primer maupun skunder. Dari pengumpulan data tersebut akan dilakukan reduksi atau memilih data valid dan tidak valid, kemudian untuk memudahkan dalam melakukan kajian, perolehan data tersebut maka penulis sajikan ke dalam tabel, selanjutnya akan dilakukan analisis serta menarik kesimpulan. Secara sederhana proses tersebut dapat diamati dalam gambar sebagai berikut:

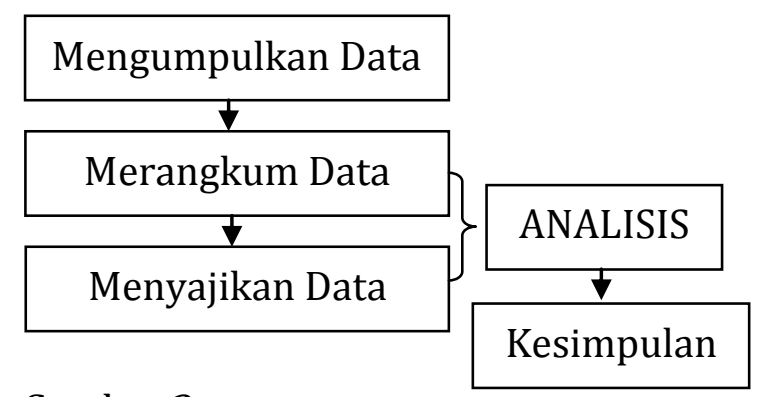

Gambar 2.

Komponen dalam Analisis Data

Sumber : Dari berbagai macam sumber

Analisis dilaksanakan setelah semua data sudah terkumpul dan telah dirangkum ke dalam bentuk tabel. Analisis data ini bertujuan untuk penyederhanaan data agar lebih mudah dibaca serta dipahami. Analisis data yang akan dilakukan dari hasil penelitian meliputi:

1. Analisis perolehan data yang bertujuan untuk mengetahi penerapan hedging yang sesuai dengan prinsip syariah.

2. Penyajian dalam bentuk tabel, tujuannya untuk mengetahui penerapan hedging yang telah dilakukan.

Analisis yang menunjukan hasil dari penerapan hedging di perbankan syariah khususnya di Indonesia dan kendala yang dialami dalam menerapkan hedging.

\section{HASIL DAN PEMBAHASAN}

\section{A. Mekanisme (Hedging) \\ Perbankan Syariah Indonesia}

PT. Bank Syariah Mandiri (BSM) adalah salah satu dari beberapa lembaga jasa keuangan yang berstatus bank devisa sejak tahun 2002. Sesuai dengan statusnya BSM menjalankan usahanya meliputi dalam dan luar negeri dan sedikit banyaknnya atas kegiatan terebut, maka BSM akan dihadapkan oleh berbagai permasalahan, salah satunya adalah permasalahan mengenai naik-turunnya nilai tukar mata uang. Oleh karena itu, BSM mengindikasi bahwa diperlukannya usatu sistem atau pengaturan guna memitigasi risiko yang dimungkinkan terjadi akibat fluktuasikurs mata uang, disamping itu, untuk memenuhi kebutuahan nasabah dan disatu sisi untuk mendukung kegiatan BSM secara maksimal.

Penelitian ini dilakukan di BSM karena BSM merupakan satu-satunya bank syariah yang telah menjalankan sistem hedging di Indonesia. Sistem hedging yang diterapkan oleh BSM berdasarkan hasil penelitian telah sesuai dengan himbauan DSN-MUI No. 96/DSNMUI/IV/2015 tentang Hedging syariah, Peraturan Bank Indonesia Nomor 18/2/PBI/2016 dan opini Dewan Pengawas Syariah BSM Nomor 17/26/DPS/XII/2015. Kesesuaian praktik hedging yang di terapkan di BSM, secara sederhana dapat diketahui dari kesesuaian terhadap kriteria-kriteria struktur pengaturan yang telah ditentukan oleh Fatwa DSN-MUI, PBI, OJK dan Beberapa Para Ahli Fikih di Indonesia. Pengaturan tersebut meliputi: Definisi tansaksi hedging, pelaku transaksi, pelaksanaan transaksi, underlying transaksi, biaya transaksi, 
pencatatan dan pelaporan transaksi serta sanksi terhadap pelanggaran taransaksi.

Praktik hedging yang dimaksud yaitu, praktik yang dilakukan oleh perbankan syariah dengan pemohon fasilitas hedging (nasabah), untuk kebutuhan yang sifatnya mendesak (lil-hajjah) dalam mekanisme forward agreement yaitu saling berkomitmen (muwa'adah) untuk melakukan akad jual-beli mata uang secara spot di masa yang akan datang (sesuai kesepakatan), dengan rangkaian at-tahawwuth al-basith dan/atau at-tahawwut murakkab yaitu lindung nilai syariah (LNS) secara komplek dan/atau sederhana. Secara sederhana mekanisme transaksinya dapat dilihat pada gambar berikut:

1. At-Tahawwut al-Basith (Sederhana)

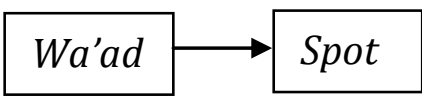

Gambar 3.

Mekanisme Hedging Sederhana

2. At-Tahawut al-Murakkab (Komplek)

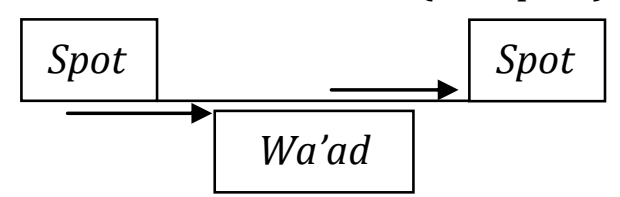

Gambar 4.

Mekanisme hedging Kompleks

Keterangan Lindung Nilai Syariah (LNS)

1. Sederhana: transaksi LNS dengan akad al-Basith yaitu skema forward agreement, ketika jatuh tempo dilakukan akad dan serahterima mata uang sesuai dengan kesepakatan secara spot.

2. Komplek: Transaksi LNS dengan sekema berupa rangkaian transaksi spot dan forward agreement, bedanya dengan poin 1 hanya terletak di transaksi spot sebelum forward agreement.

Berdasarkan rangkaian transaksi LNS di atas, maka secara sederhana dapat dipahami transaksi melaui instrumen forward agreement merupakan bentuk transaksi spot yang ditunda. Kemudian, jika dinilai lebih lanjut, instrument ini mempunyai suatu kelemahan diantaranya adalah, pemembatalan wa'ad untuk melakukan akad jual beli mata uang dikemudian hari, maka secara otomatis transaksi hedging dengan melaui rangkaian forward agreement tersebut batal. Oleh sebab itu, inilah yang disebut dengan kemudharatan (gharar) yang melekat pada transaksi hedging yang sulit dihindari dan dihilangkan (DSN-MUI, PBI dan Ahli Fikih:2016). Namun, hal ini dinilai lebih baik jika dibandingkan dengan penerapan hedging yang sudah diterapkan di Perbankan Syariah Malaysia dengan mekanisme akad murabahah dua kali sekaligus dalam satu kali transaksi. Secara sederhana mekanisme tersebut dapat diilustrasikan pada gambar berikut:

\section{Murabahah1}

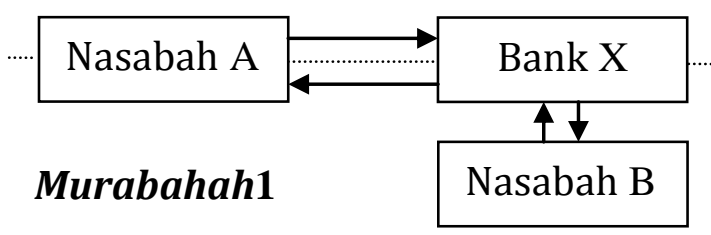

Gambar 5.

Mekanisme Hedging di Perbankan Syariah Malaysia

\section{Keterangan:}

1. Murabahah 1: Bank X membeli komoditas kepada nasabah A dengan menggunkan akad murabahah untuk tiga bulan mendatang.

2. Murabahah 2: pada waktu yang sama, Bank X menjual komoditas kepada nasabah B untuk tiga bulan ke depan.

Mekanisme LNS di atas dapat diilustrasikan sebagai berikut: pada transaksi murabahah 1, bank membeli komoditas tertentu kepada nasabah A, 
misalnya dengan jenis mata uang Ringgit Malaysia berjumlah MYR 39.700 untuk tiga bulan ke depan. Pada saat bersamaan bank $\mathrm{X}$ menjual komoditas tersebut kepada nasabah B, misal dengan jenis mata uang Dollar Amerika Serikat dengan jumlah USD 10.000 untuk tiga bulan mendatang. Dan kesepakatan nilai tukar atau kurs MYR terhadap USD yang telah disepakati adalah senilai MYR 4.000/USD.

Berdasarkan ilustrasi tersebut, maka dapat dipastikan bahwa pada tiga bulan mendatang bank $\mathrm{X}$ akan melakukan transaksi sesuai dengan kesepakatan kepada nasabah A dan B tanpa melakukan akad kembali pada saat jatuh tempo, hal ini dikarenkan bank $\mathrm{X}$ dan nasabah menggunakan akad murabahah pada saat awal transaksi. Berdasarkan penelitian terdahulu, landasan penerapan LNS tersebut adalah menggunakan hadits al-kharaj bildhaman dan prinsip al-ghumu bil gurmu, yang artinya profit itu muncul bersamaan dengan risiko, atau hak atas hasil usaha itu muncul karena adanya keharusan untuk menanggung risiko. Risiko yang dimaksud adalah jikal transaksi Bank $\mathrm{X}$ dengan nasabah $\mathrm{A}$ gagal, maka akan memperi pengaruh terhadap transaksi Bank $\mathrm{X}$ kepada nasabah B.

Berdasarkan risiko yang dimungkinkan timbul dalam praktik hedging di atas, maka selanjutnya DSNMUI dan beberapa pihak lainnya untuk mengkaji ulang instrumen hedging tersebut, hingga didapatlah hedging dengan instrumen baru yang dianggap risikonya lebih kecil dan lebih efisien. Oleh sebab itu DSN-MUI mengeluarkan fatwa yang berkenaan dengan hedging dengan mekanisme saling berjanji (muwa'adah) untuk melaksanakan akad jual beli mata uang dimasa yang akan datang. Alasan DSN-MUI menganggap insrumen ini lebih efisien, hal ini karena bank tidak harus melakukan dua kali transaksi dalam satu waktu, dan jika nasabah gagal memenuhi wa'ad pada saat jatuh tempo tidak akan menimbulkan gagalnya transaksi bank yang bersangkutan dengan nasabah lain. Secara sederhana praktik hedging yang telah diterapkan oleh perbankan syariah Malaysia dan Indonesia dapat dipahami dalam tabel berikut:

Tabel 2. Perbedaan Kontrak hedging di Perbankan syariah Malaysia dan Indonesia

\begin{tabular}{|c|c|c|}
\hline Ketentuan & Malaysia & Indonesia \\
\hline Awal & Kontrak & Kontrak \\
\hline Transaksi & $\begin{array}{l}\text { Hedging } \\
\text { dengan akad } \\
\text { murabahah }\end{array}$ & $\begin{array}{l}\text { hedging dengan } \\
\text { forwar } \\
\text { areement }\end{array}$ \\
\hline Hari & Menyerahkan & Melakukan \\
\hline Penyerahan & $\begin{array}{l}\text { kedua jenis } \\
\text { mata uang } \\
\text { tanpa } \\
\text { melakukan } \\
\text { akad. }\end{array}$ & $\begin{array}{l}\text { akad dan } \\
\text { diikuti dengan } \\
\text { penyerahan } \\
\text { kedua jenis } \\
\text { mata uang } \\
\text { (spot). }\end{array}$ \\
\hline
\end{tabular}

Sumber: Forum Seminar UIN Syarif Hidayatullah Jakarta, 17 Maret 2016

Berdasarkan tabel di atas, mekasisme lindung nilai (hedging) melalui kontrak forward agreement menurut DSN-MUI dapat dipahami sebagai berikut: pada mulanya kedua belah pihak (bank dan nasabah) besepakat/janji (muwa'adah) untuk melakukan transaksi akad jual/beli mata uang secara spot di masa (sesuai kesepakatan), kemudian pada saat hari penyerahan, kedua belah pihak baru melakukan akad jual beli secara spotdan diikuti dengan serah terima kedua jenis mata uang sesuai kesepakatan.

Berdasarkan pembahasan di atas jika ditelaah lebih lanjut, sistem hedging yang akan diterapkan oleh perbankan syariah Indonesia tidak menutup kemungkinan terdapat kelemahan, walaupun sebelumnya telah dianggap lebih efisien jika dibandingkan dengan sistem hedging di perbankan syariah Malaysia, tetap saja sistem hedging tersebut mengadung risiko. Risiko yang 
dimaksud adalah adanya kemungkinan gharar yang tidak dapat dihindarkan. Gharar yang dimaksud adalah ketidak pastian nasabah dalam melakukan akad sesuai perjanjian pada awal transaksi seperti yang telah dibahas sebelumnya.

Berkaitan dengan hal tersebut, sesuai dengan penelitian yang dilakukan dan pendapat beberapa para ahli fikih sebelumnya, jika dapat diusahakan untuk mencari alternatif lain yang dianggap pantas untuk diterapkan di perbankan syariah Indonesia, agar diusahakan untuk dapat dicari dan didiskusikan kembali, dibandingkan harus mengadopsi sesuatu yang mengandung gharar. Hal ini sesuai dengan kaidah fikih yang artinya "kemudharatan itu harus dihilangkan" (Mansoori,2010:122).

\section{KESIMPULAN DAN IMPLIKASI}

Setelah melakukan penelitan dan kajian dalam pembahasan mengenai "Analisis Penerapan Hedging di Perbankan Syariah Indonesia (Studi pada Bank Syariah Mandiri)" maka, penelitian ini dapat disimpulkan sebagai berikut:

1. Penerapan hedging di perbankan syariah Indonesia, khususnya BSM mengikuti ketentuan PBI No. 18/2/PBI/2016, Fatwa No.96/DSNMUI/IV/2015 , opini DPS No. 17/26/DPS/XII/2015 serta POJK No. 24/POJK.03/2015. Dan untuk sementara penerapan hedging di perbankan syariah Indonesia khususnya di BSM belum dapat dilaksanakan secara maksimal.

2. Faktor penyebab terhambatnya penerapan hedging di perbankan syariah Indonesia khususnya di BSM untuk sementara, sebagai berikut:

a. Masih terbatasnya pengetahuan nasabah maupun pihak bank mengenai akad dan wa'ad terkait impelementasiannya dalam kontrak perjanjian hedging,

b. Lamanya rentang waktu dalam melakukan perumusan hedging oleh pihak BI,OJK, DSN-MUI maupun pihak terkait lainnya,

Belum tersedianya sistem untuk input data mengenai laporan harian umum bank (LHBU) oleh pihak BI, sehingga hal ini menyebabkan tidak bersedianya bank counterparty untuk melakukan hedging syariah, serta belum tersedianya standar operasional prosedur (SOP) maupun manual operasional (MO) oleh pihak bank. khususnya di BSM.

\section{DAFTAR PUSTAKA}

Naskah jurnal atau abstrak.

Zam, Agus Fajri, Setiawan Budi Utomo dan Iwan Kurniawan hadianto (1997), Analisis Kesesuaian Konsep Hedge Konvensional terhadap Prinsip Syariah.

Buku

Al-Albani, Muhammad Nashruddin. (2015). Shahih At-Targhib wa AtTarhib (Terjemahan). Jakarta: Darul Haq.

Ascarya. (2012). cetakan ke-4. Akad dan Produk Bank syariah, Akad dan produk Bank Syariah Malaysia dan Indonesia. Jakarta: Rajawali.

Cahyono, Bambang Tri (1996). Manajemen Strategi, Fungsi Manajemen. Jakarta: IPWI.

Indriantoro, Nur bambang Supomo (1999). Metodologi Penelitian Bisnis, Untuk Akuntansi dan Manajemen. Yogyakarta: BPFE, Anggota IKPI.

Iska, Syukri. (2012). Sisitem Perbankan Syariah di Indonesia dalam Perspektif Fiqih Ekonomi, Asas, Fungsi dan Aturan Perbankan di Indonesia. Yogyakarta: Fajar Media. Karim, Adiwarman A. (2007). Bank Islam, Analisis Fiqih dan Keuangan. 
Menejemen Risiko Bank Syariah. Jakarta: Raja Grafindo Persada.

Kasmir. (2013). Bank dan Keuangan Syariah. Jakarta: Rajawali

M. Yusanto, Ismail dan M. Arif Yunus. (2009). Pengantar Ekonomi Islam. Bogot: Al-Azhar Press

Mansoori, Muhammad Toher (2010) Kaidah-kaidah Fiqih Keuangan dan Transaksi Bisnis. Bogor: Ulil Albab Institute.

Muhammad dan Dwi suwikno. (2009). Akuntasi perbankan Syariah, Pengakuan dan Pengukuran dalam Akuntasi Perbankan Syariah, Pengakuan dan Pengukuran Sharf. Yogyakarta: TrustMedia.

Muhyiddin Athiyyah. (2009). Kamus Ekonomi Islam. Surakarta: Ziyad Visi Media

Rax, Raflus. (1996). Treasury management (Banking and Corporate). Jakarta: 18 November 1996.

Sugiyono. (2005). Memahami Penelitian Kualitatif, Bandung: Alfabeta

Taqiyuddin, an-Nabhani (2010). Sistem Ekonomi Islam, Kurs Pertukaran Mata Uang, dan Interaksi Uang Antar Negara. Bogor: Al-Azhar.

Tarmizi, Irwandi (2015). Harta haram Muamalat Kontemporer, Hedging Syariah. Bogor: PT. Berkat Mulya Insani.

Yusanto, M. Ismail, M. Arif Yunus. (2009). Pengantar Ekonomi Islam. Bogor. Al-Azhar Press.

Laporan pada pertemuan ilmiah (konferensi, workshop, dll) yang tidak tercakup dalam buku atau proseding.

Bank Indonesia. (2016). Hedging Syariah (at-tahawuth al-Islami). Program Pnedalaman Pasar Keuangan. Seminar Nasional Transaksi Lindung Nilai Syariah (at-thawwuth alIslami/Islamic Hedging) Perspektif Fatwa, Regulasi dan Praktik. UIN Syarif Hidayatullah Jakarta.
DSN-MUI. (2016). Urgensi Penerbitan Fatwa tentang Transaksi Lindung Nilai Syariah Atas Nilai Tukar. Seminar Nasional Transaksi Lindung Nilai Syariah (at-thawwuth alIslami/Islamic Hedging) Perspektif Fatwa, Regulasi dan Praktik. Jakarta: UIN Syarif Hidayatullah.

Hosen, Nadratuzzaman. (2016). Praktik Hedging di Berbagai Negara. Seminar Nasional Transaksi Lindung Nilai Syariah (at-thawwuth alIslami/Islamic Hedging) Perspektif Fatwa, Regulasi dan Praktik. Jakarta: UIN Syarif Hidayatullah.

JFX. (2016). Implementasi Transaksi Hedging Syariah di Bursa Komoditi. Seminar Nasional Transaksi Lindung Nilai Syariah (at-thawwuth alIslami/Islamic Hedging) Perspektif Fatwa, Regulasi dan Praktik. Jakarta: UIN Syarif Hidayatullah.

Karim, Adiwarman A. (2016). Konsep dan Urgensi Hedging Syariah dalam Upaya Mitigasi Risiko di Lembaga Keuangan Syariah. Seminar Nasional Transaksi Lindung Nilai Syariah (atthawwuth al-Islami/Islamic Hedging) Perspektif Fatwa, Regulasi dan Praktik. Jakarta: UIN Syarif Hidayatullah.

Otoritas Jasa Keuangan. (2016). Kabijakan Regulasi OJK Terkait Produk dan Pengaturan Hedging Syariah. Seminar Nasional Transaksi Lindung Nilai Syariah (at-thawwuth al-Islami/Islamic Hedging) Perspektif Fatwa, Regulasi dan Praktik. Jakarta: UIN Syarif Hidayatullah.

Karya Ilmiah Lepas yang dimuat pada Website.

Bank Indonesia. (2014). Surat Edaran Nomor 16/5/DPM/2014 tanggal 8 April 2014 Tentang Perubahan Ketiga Atas Surat Edaran Bank Indonesia Nomor 7/23/DPD/2005 tanggal 8 Juli 2015 Pembatasan Transaksi dan Pemberian Kredit Valuta Asing oleh Bank. 
Bank Indonesia. (2016). Peraturan Bank Indonesia Nomor 18/2/PBI/2016 tanggal 24 Februari 2016 Tentang Transaksi Lindung Nilai Berdasarkan Prinsip Syariah. Diakses dari http://www/bi.go.id

Bank Syariah Mandiri. (2015). Opini Dewan Syariah Nomor 17/26/DPS/XII/2015 tanggal 28 Desember 2015 Tentang Rencana Transaksi Lindung Nilai (Hedging) Syariah. 